Diabetologia 11, 249-253 (1975)

(C) by Springer-Verlag 1975

\title{
Small and Large Vessel Disease in the Development of Foot Lesions in Diabetics
}

\author{
I. Faris \\ The Middlesex Hospital, London, England \\ Received: October 28, 1974, and in revised form: April 1, 1975
}

\begin{abstract}
Summary. This paper describes studies undertaken to determine the role of vascular disease in the development of foot lesions in diabetics, particularly those with neuropathy. The ratios of ankle/arm and toe/ankle blood pressure were used as indices of large and small vessel disease respectively. Diabetic patients with lesions had evidence of more large and small vessel disease than patients without lesions. Patients
\end{abstract}

with neuropathic lesions had evidence of more small vessel disease than patients without lesions.

Key words: Diabetic angiopathy, atherosclerosis, strain gauge plethysmography, toe blood pressure measurement, neuropathic foot lesions, perforating ulcer.
The foot lesions which develop in patients with diabetes mellitus were regarded for many years as being due to vascular disease. Since the studies of Oakley, Catterall and Martin [9] the importance of neuropathy has been increasingly recognised, so that a recent account of the pathogenesis of these lesions [3] discounts vascular disease as a factor in the development of ulcers of the sole of the foot. The role of vascular changes has not been frequently studied, especially when the arterial supply is apparently normal. The assessment of vascular disease in the foot is almost entirely subjective, although changes in small arteries, arterioles and capillaries probably occur as part of the widespread vascular disease occurring in diabetics. The measurement of digital blood pressure using a strain gauge technique has recently been described [5,8] and provides a suitable objective method of study.

Oakley, Catterall and Martin [9] describe and illustrate the lesions they associate with neuropathy. These include perforating ulcers and areas of gangrene on the feet and toes. Lesions with the appearance described in a patient with neuropathy and without significant atherosclerosis in the legs can be described as being primarily neuropathic in origin. This paper describes studies undertaken on a group of diabetic patients with neuropathy and/or vascular disease in their legs, in order to determine the role of vascular disease in the development of their lesions. Particular attention was paid to the vascular changes in a group of patients with neuropathic lesions and an apparently normal arterial supply.

\section{Materials and Methods}

\section{Plan of Study}

Resting, recumbent patients were studied. A mercury-in-silastic strain gauge placed around the great toe was used as a pulse detector. This was connected via a Parks model 210 Plethysmograph to a recorder (Devices model M 2) so that a continuous recording of the pulse wave could be obtained. Toe and ankle systolic blood pressures were measured using occluding cuffs placed, respectively, around the base of the toe and around the ankle. The toe cuff measured $2 \times 12 \mathrm{cms}$ and the ankle cuff $24 \times 14 \mathrm{cms}$. Arm systolic blood pressure was measured by means of a cuff above the elbow and a strain gauge around the thumb. Systolic pressure was defined as the pressure at which the first detectable pulsation occurred during slow deflation of the cuff from suprasystolic levels. At least three recordings of each pressure were made and the mean value used.

\section{Patients Studied}

\section{Group I}

Non-Diabetics. 29 patients. These patients had no clinical features or family history of diabetes and were free of glycosuria on repeated examination of the urine. There was no evidence of significant peripheral occlusive vascular disease.

\section{Group II}

Diabetics without Foot Lesions. Thirty-two patients were studied from an unselected group of diabetic inpatients and out-patients.

\section{Group III}

Diabetics with foot Lesions. 26 patients. All these patients required admission to hospital for assessment and treatment of their foot condition. The lesions comprised 17 patients with perforating ulcers of the sole of the foot, 8 patients with patchy gangrene of the toes and/or heel. One patient had both types of lesions. 
The appearance of all these lesions is compatible with the description of neuropathic lesions [9].

From Table I it can be seen that all the patients had evidence of peripheral neuropathy. In addition, the three patients who were tested out of the four in whom there was no detectable sensory loss had slowing of nerve conduction in the tibial and common peroneal nerves.

Table 1. Neurological status of diabetic patients

\begin{tabular}{lll}
\hline & $\begin{array}{l}\text { Diabetics } \\
\text { without } \\
\text { lesions }\end{array}$ & $\begin{array}{l}\text { Diabetics } \\
\text { with } \\
\text { lesions }\end{array}$ \\
\hline $\begin{array}{l}\text { Leg reflexes } \\
\text { Knee jerk present } \\
\text { Ankle jerk present } \\
\text { Knee jerk present } \\
\text { Ankle jerk absent }\end{array}$ & 14 & 0 \\
$\begin{array}{l}\text { Knee jerk absent } \\
\text { Ankle jerk absent }\end{array}$ & 9 & 4 \\
$\begin{array}{l}\text { Sensation in leg } \\
\text { Intact } \\
\begin{array}{l}\text { Vibration sense decreased } \\
\text { at ankle }\end{array}\end{array}$ & 15 & 22 \\
$\begin{array}{l}\text { Light touch and pinprick } \\
\text { decreased on foot }\end{array}$ & 5 & 6 \\
\hline
\end{tabular}

Detailed clinical examination was carried out on all patients with particular attention given to evidence of cardiovascular disease, peripheral neuritis and retinopathy. A summary of the basic clinical information is given in Table 2 .

Table 2. Details of groups studied (mean $\pm I S D$ )

\begin{tabular}{lrrr}
\hline & $\begin{array}{l}\text { Group I } \\
\text { Normal } \\
\text { subjects }\end{array}$ & $\begin{array}{l}\text { Group II } \\
\text { Diabetics } \\
\text { without } \\
\text { lesions }\end{array}$ & $\begin{array}{l}\text { Group III } \\
\text { Diabetics } \\
\text { with } \\
\text { lesions }\end{array}$ \\
\hline Age & $54.3 \pm 15.2$ & $55.2 \pm 17.7$ & $60.7 \pm 10.2$ \\
$\begin{array}{c}\text { Arm blood } \\
\text { pressure } \\
\begin{array}{c}\text { Duration of } \\
\text { diabetes }\end{array}\end{array}$ & $121.2 \pm 14.3$ & $133.6 \pm 28.0$ & $146.7 \pm 32.5$ \\
\hline
\end{tabular}

\section{Statistical Methods}

Ratios were compared using a Wilcoxon sum of ranks test. Multiple regression analysis was carried out using a programme of stepwise regression ${ }^{1}$ in the CDC 7600 computer of London University Computer Centre.

1 (BMD 02R) Health Services Computing Facility UCLA)

\section{Results}

The ankle/brachial pressure ratio was used as an index of occlusive disease above the ankle (large vessel disease). The toe/ankle pressure was used as an index of occlusive disease in the foot (small vessel disease).

\section{Evidence of Large Vessel Disease}

The ankle/brachial pressure ratios for each group of patients are shown in Fig. 1. There is no significant difference between the normal patients and those dia-

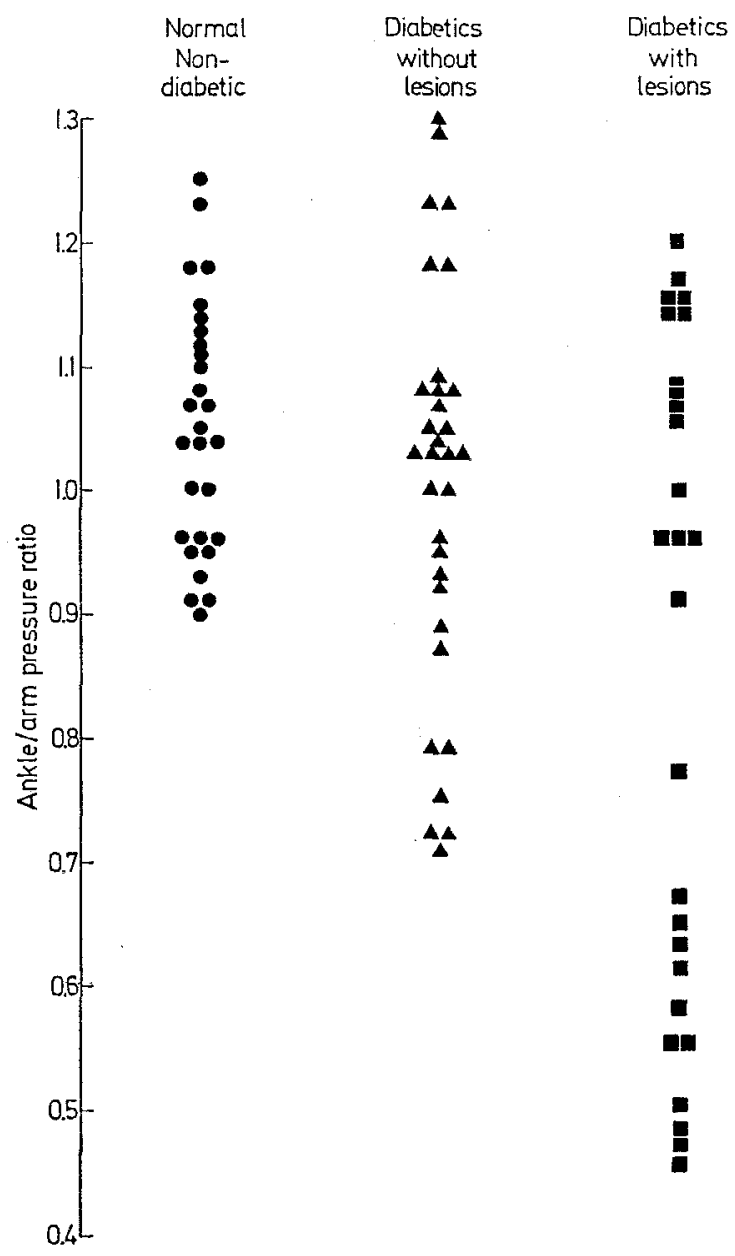

Fig. 1. Ankle/arm pressure ratio in groups of patients studied

betics without lesions. Diabetics with lesions had a significantly lower ankle/brachial pressure ratio than diabetic patients without lesions $(p<0.05)$. Twelve of the 26 patients with lesions had a moderate degree of large vessel disease (ankle/brachial pressure ratio $0.4-0.8$ ), but the remaining 14 patients were, when judged by this criterion, free of significant occlusive disease in the leg. 


\section{Evidence of Small Vessel Disease}

The toe/ankle pressure ratios for all the patients are shown in Fig. 2. Diabetic patients without lesions have evidence of more small vessel disease than normal patients $(p<0.05)$ and diabetics with lesions have lower toe/ankle pressure ratios than those without lesions $(p<0.01)$.

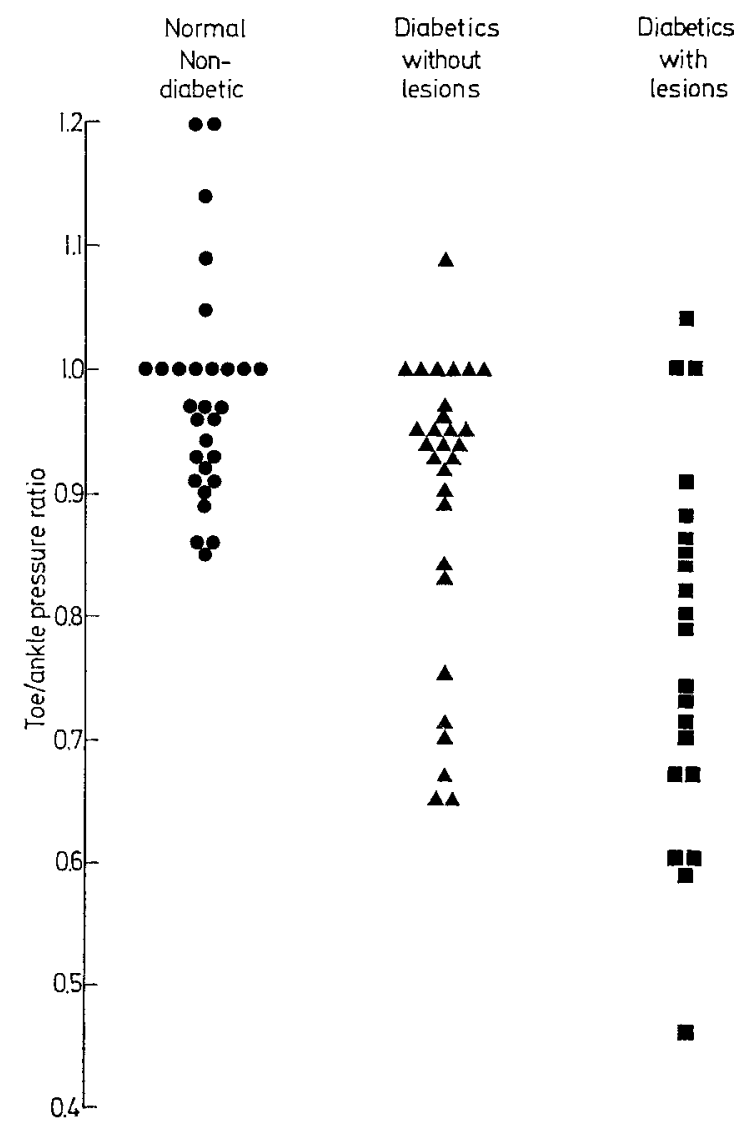

Fig. 2. Toe/ankle pressure ratio in groups of patients studied

\section{Small Vessel Disease in Patients Free of Large Vessel Disease}

In order to eliminate the possible effects of atherosclerosis in the legs in the development of lesions, those patients in Groups II and III who had a normal ankle/brachial pressure ratio (greater than 0.9) were studied further. This included 24 patients in Group II and 14 patients in Group III; 12 with penetrating ulcers and 2 with gangrene of a toe. These Group III patients had lesions of the foot in the presence of neuropathy, but in the absence of significant atherosclerosis in the legs.

The results of comparing the toe/ankle pressure ratios in these patients are shown in Fig. 3. The significant difference between the patients from Groups II and III persists $(p<0.05)$. Thus, in the absence of demonstrable large vessel disease, there is an increased severity of small vessel disease in the patients with lesions.

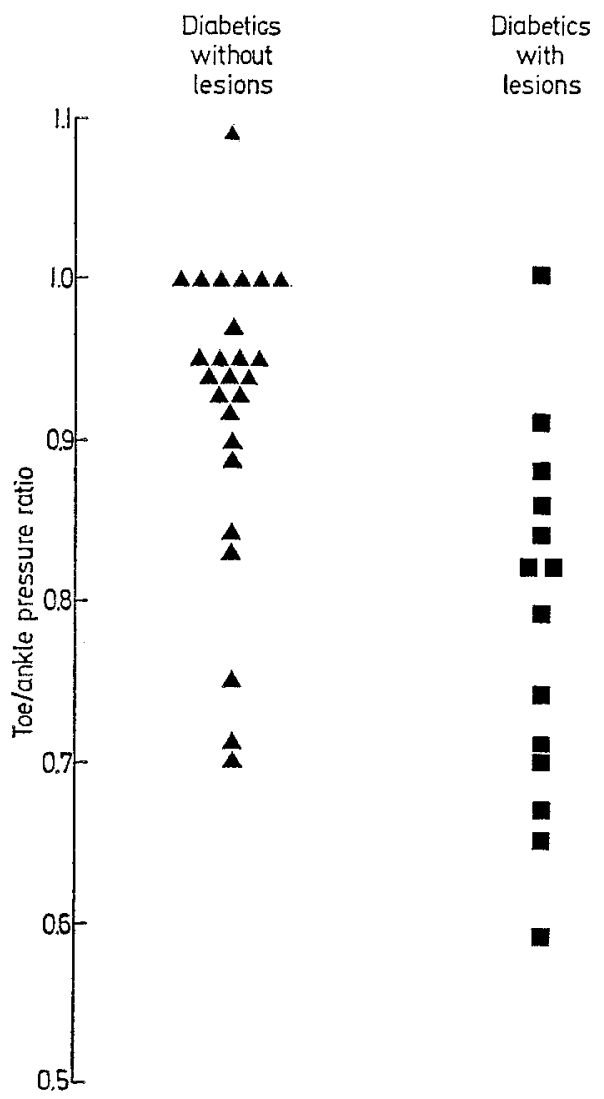

Fig. 3. Toe/ankle pressure ratios in patients in groups II and III who were free of significant large vessel disease (i.e. ankle/arm ratio $<0.9$ )

\section{Factors Influencing the Development of Occlusive Vascular Disease}

The occurrence of three of the factors which might lead to the development of occlusive vascular disease are shown in Table 2. Although the differences between the diabetic groups for each individual factor are not significant, a difference in the occurrence of large vessel disease (Fig. 1) might have been responsible for the observed differences in the toe/ankle ratio (Fig. 2 and 3). Multiple regression analysis was used to determine if any of these factors significantly influenced the toe/ankle pressure ratio. The regression coefficients for the diabetic group considered as a whole are shown in Table 3.

Age is the only significant predictor of the toe/ ankle ratio. The duration of diabetes, arm blood pressure and the presence of atherosclerotic occlusion of the vessels above the ankle do not significantly contribute to the prediction of the toe/ankle pressure. 
Table 3. Correlation coefficients for stepwise regression for variables as predictors of toelankle ratio

\begin{tabular}{llll}
\hline Variable & $\begin{array}{l}\text { Multiple } \\
\mathrm{R}\end{array}$ & $\begin{array}{l}\text { F value to } \\
\text { enter or } \\
\text { remove }\end{array}$ & $\mathrm{p}$ \\
\hline $\begin{array}{l}\text { Age } \\
\text { Ankle/brachial } \\
\text { pressure ratio }\end{array}$ & 0.3022 & 4.3209 & $<0.05$ \\
$\begin{array}{l}\text { Duration of diabetes } \\
\text { Arm blood pressure }\end{array}$ & 0.3130 & 0.3099 & $\mathrm{NS}$ \\
\hline
\end{tabular}

\section{Discussion}

The importance of neuropathy in the pathogenesis of foot lesions in diabetic patients has been widely recognised since the report of Oakley, Catterall and Martin [9]. Vascular disease is also acknowledged as a cause of foot problems, but the associations between the two have not been explored. The use of the mercury strain gauge and the Doppler ultrasound technique for the measurement of segmental blood pressures in the limb provide objective methods of study. The measure of toe blood pressure described here allows study of a more distal segment of the vascular tree. The use of this technique has also been described by Gundersen [5] and applied to diabetic subjects [8]. The ankle and arm pressures measured by the strain gauge technique correlate well with the brachial and ankle pressures measured using the Doppler ultrasound method (unpublished observations by author). Thus the ankle/arm ratio used here is equivalent to the pressure index of Yao [11] which relates well to the clinical severity of atherosclerotic disease in the legs.

The patients with lesions fall into two groups. Twelve patients had evidence of significant atherosclerosis and the lesions could have been due to ischaemia or to the combined effects of ischaemia and neuropathy. In most of these patients the outcome will be determined by the severity of the vascular disease. This finding supports the general role of atherosclerosis in the development of lesions in diabetics. The remaining 14 patients had lesions typically associated with neuropathy in the absence of demonstrable atherosclerosis in the legs, i.e. primarily neuropathic lesions. These patients were selected for further study. There is clear evidence for the association between low toe/ankle ratio and the development of lesions in these patients. This finding has not previously been described This index of obstruction to the vessels of the foot is independent of the presence of atherosclerosis in the legs, the presence of hypertension and the known duration of diabetes, although this is an imprecise measurement in mature onset diabetes.

The relationship between age and vascular disease in diabetics is still controversial. Some [2] suggest that the vascular disease is related to the duration of diabetes, while others [10] believe that the vascular disease is more related to the age of the subject. Our findings support the latter conclusion, at least as far as small vessel disease is concerned. Although there have been several studies in which the blood flow in diabetics has been measured $[1,2,7]$ there have been few attempts to relate vascular changes to the development of lesions. Moore and Frew [6] found evidence of microscopic disease of arterioles and capillaries in $30 / 34$ patients with lesions and these changes were more frequent and severe than in patients without lesions. Ferrier [4] found that in patients who had major amputations the metatarsal arteries were more often occluded in diabetic than in non-diabetic patients. The findings reported in this paper provide a clear demonstration "in vivo" of the presence of obstruction to the vessels of the foot and support the conclusions derived from histological examination $[4,6]$. The dissociation between small and large vessel disease described here may be because less narrowing is required to produce a large pressure drop in small vessels than in large vessels, so that the methods used are more sensitive for detecting small vessel disease than they are for detecting large vessel disease.

The importance of these changes in the development of lesions is unproven. Assuming that neuropathy is the primary cause $[3,9]$, the co-existence of arterial disease could potentiate the development and persistence of an ulcerated lesion and, in this way, the two processes may be synergistic in their action.

Acknowledgements. The patients studied were under the care of Dr. J. D. N. Nabarro and Professor L. P. Le Quesne, whose help is gratefully acknowledged. Mr. P. Whitfield performed the multiple regression analysis. The work was supported by a John Astor Fellowship from The Middlesex Hospital Medical School. Based on a communication to the Surgical Research Society, London. January, 1974.

\section{References}

1. Butterfield, W. J. H., Keates, J. J.: Plethysmographic studies of foot blood flow in diabetes. Diabetologia 4 , 377 (1968)

2. Christensen, N. J.: Spontaneous variation in resting blood flow, postischaemic peak flow and vibratory perception in the feet of diabetics. Diabetologia 5, 171-178 (1969)

3. Ellenberg, M.: Diabetic neuropathic ulcer. J. Mt Sinai Hosp. 35, 585-594 (1968)

4. Ferrier, T. M.: Comparative study of arterial disease in amputated lower limbs from diabetics and non-diabetics (with special reference to foot arteries). Med. J. Aust. 1, $5-11(1967)$ 
5. Gundersen, I.: Segmental measure of systolic blood pressure in the extremities, including the thumb and the great toe. Acta. chir. scand. Suppl. 426 (1972)

6. Moore, J. M., Frew, I. D, O.: Periperal vascular lesions in diabetes mellitus. Brit. med. J. 1965 II, 19-23

7. Munck, O., Lindbjerg, I. F., Binder, C., Lassen, N. A. Trap-Jensen, J.: Skeletal muscle blood flow in diabetic patients determined by intramuscular injection of Xenon $^{133}$. Diabetes 15, 323-326 (1966)

8. Neilsen, P. E., Rasmussen, S. M.: Indirect measurement of systolic blood pressure by strain gauge technique at finger, ankle and toe in diabetic patients without symptoms of occlnsive arterial disease. Diabetologia 9, 25-29 (1973)
9. Oakley, W., Catterall, R. C. F., Martin, M. M.: Aetiology and management lesions of the feet in diabetes. Brit. med. J. 1956 II, 953-957

10. Oakley, W. G., Pyke, D. A., Taylor, K. W.: Clinical diabetes and its biochemical basis, pp. 522-529. Oxford: Blackwell Scientific Publications 1968

11. Yao, S. T.: Haemodynamic studies in peripheral arterial disease. Brit. Surg. 57, 761-766 (1970)

Dr. I. Faris

Dept. of Surgery

Perth Medical Centre

Shenton Park, W.A. 6008

Australien 